\title{
The Effects of Blue LED Light on Behavior and Retinal Function in Maternal and Offspring Mice
}

\author{
Megumi Horibe*, Yuta Yoshino*, Shinichi Domoto, Maho Nakamura, \\ Masamitsu Shimazawa, Hideaki Hara \\ Molecular Pharmacology, Department of Biofunctional Evaluation, Gifu Pharmaceutical University, Gifu, Japan \\ Email: hidehara@gifu-pu.ac.jp
}

How to cite this paper: Horibe, M., Yoshino, Y., Domoto, S., Nakamura, M., Shimazawa, M. and Hara, H. (2017) The Effects of Blue LED Light on Behavior and Retinal Function in Maternal and Offspring Mice. Journal of Behavioral and Brain Science, 7, 348-359.

https://doi.org/10.4236/jbbs.2017.78026

Received: July 3, 2017

Accepted: August 14, 2017

Published: August 17, 2017

Copyright $\odot 2017$ by authors and Scientific Research Publishing Inc. This work is licensed under the Creative Commons Attribution International License (CC BY 4.0).

http://creativecommons.org/licenses/by/4.0/

(c) (i) Open Access

\begin{abstract}
In the present study, we investigated whether blue light emission diode (LED) light exposure affects the maternal behavior of mice. The brain function of the offspring mice, including short-term memory, locomotor activity, anxiety-like behavior, and depression-like behavior, was evaluated. Pregnant mice at day 11 were housed in the apparatus for exposure to blue LED light during the daytime. Nesting behavior and the survival of pups were observed until weaning. After weaning, the offspring mice were bred in normal light conditions until 12 weeks old, and then the Y-maze test, open field test, and tail suspension test were performed. Retinal functions were evaluated by electroretinogram and histological analysis. Blue LED light exposure during the daytime induced retinal damage, but did not affect behavior related to maternal care in maternal mice. In the offspring mice, blue LED light exposure during the daytime did not affect the retina or brain functions. These findings suggest that blue LED light during the daytime might not be a risk factor for disruption of the mother-infant relationship or offspring brain development in mice.
\end{abstract}

\section{Keywords}

Blue LED Light, Maternal Behavior, Daytime, Retina, Brain

\section{Introduction}

Recently, exposure to light emission diode (LED) light has increased due to the emergence of digital devises containing video displays such as personal comput-

*Authors contributed equally. 
ers, smart phones, and the other devices that use illumination. Video displays emit a large amount of blue light $(400-500 \mathrm{~nm})$, and blue light has been reported to be harmful to the retina [1] [2]. Previously, we reported the harmful effects of blue LED light to the retina in vitro and in vivo [2] [3]. On the other hand, blue LED light has been reported to regulate the circadian rhythm [4] [5], and glucose metabolism [6]. However, an unknown physiological effect of blue LED light for higher brain function may be still present and needs to be clarified.

White LED light may be spreading to companies supplying experimental animals and biomedical research institutions to reduce the consumption of electricity in the near future. Thus, it is critical to elucidate the effects of LED light on breeding behavior and physiology in housed animals. However, there are few studies to date evaluating the effects of LED light.

Maternal behavior is common to mammals, and includes nursing, nest building, maternal aggression, licking, grooming, retrieving and other behaviors [7] [8]. Since the mother-infant relationship is indispensable for species continuation, the basic brain mechanisms that control maternal behavior are considered to be well conserved in evolution [9]. Previous reports showed that disruption of the mother-infant relationship induced cognitive and emotional dysfunction [10]. It is an important finding that environmental factors can affect maternal behavior to research for mental diseases which derive from stressors in the developmental stage of brain.

In the present study, we investigated whether blue LED light exposure affects the maternal behavior of mice. Furthermore, the brain function of the offspring mice, including short-term memory, locomotor activity, anxiety-like behavior, and depression-like behavior, was evaluated.

\section{Materials and Methods}

\subsection{Animals}

Pregnant ICR mice were purchased from Japan SLC (Shizuoka, Japan) at day 10 of pregnancy. Pregnant females and pups were housed individually in specific pathogen-free conditions with ALPHA-dri (Shepherd Specialty Papers, USA) bedding. Animals were housed at $24^{\circ} \mathrm{C} \pm 2{ }^{\circ} \mathrm{C}$ under a 12 -hr light cycle (8:00 to 20:00) and had access to food and water ad libitum. In this experiment, 10 dams were used and total 136 pups were produced. Then, total 26 male offsprings were used for behavioral tests for brain functions. All procedures relating to animal care and treatment conformed to the animal care guidelines issued by the Gifu Pharmaceutical University Animal Experiment Committee. The protocol for this study was approved by the Committee on the Ethics of Animal Experiments of the Gifu Pharmaceutical University.

\subsection{Exposure to Blue LED Light at Subjective Daytime}

Female mice at day 11 of pregnancy were exposed to 100 lux of blue LED light (12 hr per day, 4 weeks, lights on 8:00) (World Trading Co., Ltd, Kanagawa, Japan). To mimic the light from a display of smart phones (measured at $10 \mathrm{~cm}$ 
distance), the intensity (100 lux) was chosen. The ambient temperature during exposure to blue LED light was maintained at $24^{\circ} \mathrm{C} \pm 2{ }^{\circ} \mathrm{C}$. Control mice were housed in conditions with 20 to 50 lux of fluorescent light.

\subsection{Measure of Maternal Behavior}

\subsubsection{Nesting Behavior}

As one of assessment of maternal behavior, nest building was measured as previously described [11] [12]. Nests were observed daily from the outside of cages. The quality of the nest was determined using following scale; score 0 , a nest was not built or unidentified; score 1, a flat nest can be identified; score 2, a nest that looks like a soup plate; score 3 , a hemisphere-like nest with a consecutive bank.

\subsubsection{Survival Rates of Pups}

The number and the average body weights of newborn pups were measured daily. To minimize environmental changes, the body weights of maternal mice and their pups were measured no earlier than 3 days after delivery. Throughout the experiment, mice were monitored for any sign of injury or weakness.

\subsection{Behavioral Tests in Male Offspring Mice from Blue LED Light-Exposed Dams}

After the experiment for maternal behavior, the pups brought up by maternal mice that had been exposed to blue LED light for 4 weeks were grown in normal light conditions until 12 weeks old. To assess the effects of exposure to blue LED light during childhood on the brain development, offspring mice were exposed to blue LED light together with their dams during the childhood period (postnatal day 0 to 21 ), then were brought up at 12 weeks old in normal light conditions.

\subsubsection{Open Field Test}

The open field test was performed to assess locomotor activity and anxiety-like behavior, as previously described [13]. Mice were placed in an open field apparatus (length $30 \mathrm{~cm} \times$ width $30 \mathrm{~cm} \times$ height $30 \mathrm{~cm}$ ) that was made of wood. The mouse was allowed to explore the apparatus for $60 \mathrm{~min}$. In this test, the behavior of the mouse was recorded. Before starting a new trial, the apparatus was cleaned with $70 \%$ ethanol and dried using paper towels and a fan to minimize the influence of odor. The total distance moved was measured from the video file using a computer-operated EthoVision XT system (Noldus, Wageningen, Netherlands). The time spent in the central zone (length $15 \mathrm{~cm} \times$ width $15 \mathrm{~cm} \times$ height $15 \mathrm{~cm}$ ) was used as a marker of anxiety-like behavior.

\subsubsection{Y-Maze Test}

The Y-maze test was performed to assess short-term memory, as previously described [14]. The Y-maze was made of three gray plastic arms (length $40 \mathrm{~cm} \times$ width $10 \mathrm{~cm} \times$ height $12 \mathrm{~cm}$ ). After habituation for an hour, each mouse was placed in the end of an arm and allowed to freely explore the maze for $8 \mathrm{~min}$. 
During the test, behavior was recorded. The number and order of the arms entered were counted from the video file. Entering each of three arms in turn was defined as an alternation. Alternation was calculated by the following formula: Alternation (\%)

$=[$ the number of actual alternations $/$ the total number of entering each arm -2$] \times 100$

\subsubsection{Tail Suspension Test}

The tail suspension test was performed to assess depression-like behavior, as previously described [15]. Each mouse was suspended by the tail with a $50 \mathrm{~cm}$ strip of surgical tape above the floor, and their behavior was recorded for $8 \mathrm{~min}$. Immobility time was measured automatically using a computer-operated EthoVision XT system. Mice were determined to be immobile when the mobility score of the system was less than $10 \%$.

\subsection{Electroretinogram}

Electroretinogram (ERG) was recorded 7 days after blue LED light exposure in maternal mice and 12 weeks after blue LED light exposure to dams in male offspring. The mice were housed in a completely dark room for $24 \mathrm{hr}$ (dark adaptation), after which they were anesthetized using ketamine $(120 \mathrm{mg} / \mathrm{kg}$, i.p.; Daiichi-Sankyo, Tokyo, Japan) and xylazine $(6 \mathrm{mg} / \mathrm{kg}$, i.p.; Bayer Health Care, Tokyo, Japan). The pupils were dilated with $2.5 \%$ phenylephrine and $1 \%$ tropicamide (Santen Pharmaceuticals, Osaka, Japan). In the left eyes of dark-adapted mice, flash ERG was recorded by placing a gold ring electrode (Mayo, Aichi, Japan) in contact with the cornea and a reference electrode (Nihon Kohden, Tokyo, Japan) on the tongue. A neutral electrode (Nihon Kohden) was inserted subcutaneously near the tail. High pass filtering $(0.3 \mathrm{~Hz})$ and low pass filtering $(500 \mathrm{~Hz})$ were used. All procedures were performed under red twilight, and mice were kept on heating pads (Mycoal, Tochigi, Japan) to maintain a steady body temperature during ERG recordings. The amplitude of the (a) wave was measured from the baseline to the maximum (a) wave peak, and the (b) wave was measured from the maximum (a) wave peak to the maximum (b) wave peak.

\subsection{Histological Analysis}

After ERG recording, the mice were euthanized by decapitation. Each eye was enucleated and kept immersed for $24 \mathrm{hr}$ at $4^{\circ} \mathrm{C}$ in a fixative solution containing $4 \%$ paraformaldehyde. Three paraffin-embedded sections (thickness $5 \mu \mathrm{m}$ ) were cut from the optic disc, which were prepared in the standard manner. Retinal sections were stained with hematoxylin and eosin. Retinal images were photographed by light microscopy (BZ-X710; Keyence, Osaka, Japan), and the thickness of the outer nuclear layer (ONL) from the optic disc was measured at 240 $\mu \mathrm{m}$ intervals. Data from these sections were averaged for each eye.

\subsection{Statistical Analyses}

All data are expressed as the mean \pm standard error of the mean (SEM). Statis- 
tical comparison was made using Student's t-tests or Mann-Whitney U tests (Figure $1(\mathrm{~A})$ ). A value of $p<0.05$ was considered to be significant.

\section{Results}

\subsection{Blue LED Light Exposure Did Not Affect Maternal Behavior}

To investigate the effects of blue LED light exposure during the daytime on maternal care in maternal mice, we observed their nesting behavior, the number of pups, and the body weight of pups.

We evaluated nesting behavior as a measure of maternal care related behaviors. All of the maternal mice built nests, and the scores of nests did not differ between each group $(p=0.85, \mathrm{n}=5$, Figure $1(\mathrm{~A}))$. The number of pups from blue LED light-exposed mice did not differ from control mice (postnatal day 23; $p=0.14, \mathrm{n}=5$, Figure $1(\mathrm{~B}))$. Moreover, the survival rate or the development of pups did not differ between each group (postnatal day 23; $p=0.62, \mathrm{n}=5$, Figure $1(\mathrm{C})$ ).
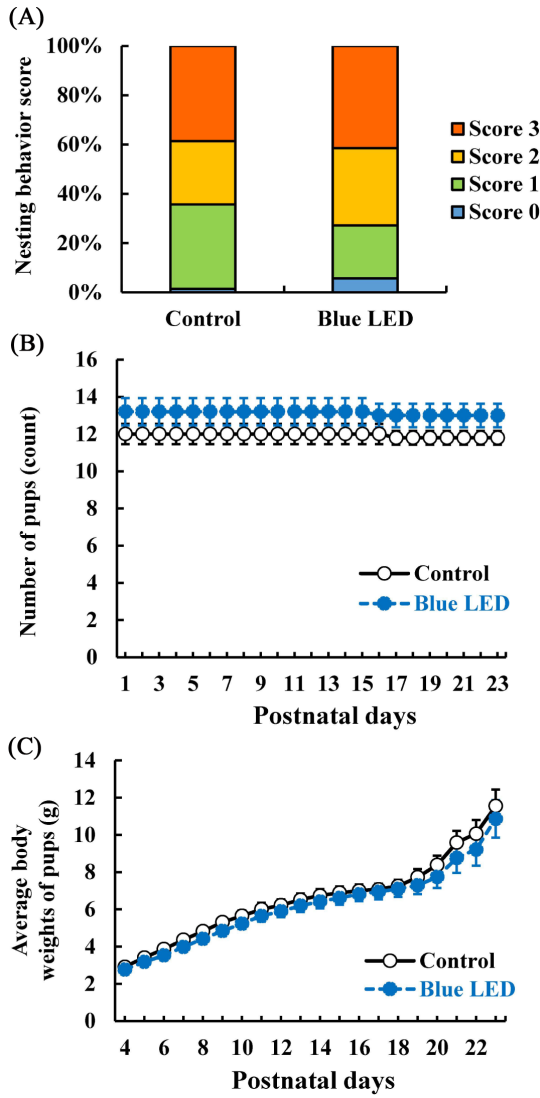

Figure 1. Evaluation of maternal behaviors by exposure to blue LED light in maternal mice. (A) Nesting behavior was measured on postnatal day 1 to 14 . The quality of the nest was determined using the following scale; score 0 , a nest was not built or unidentified; score 1, a flat nest can be identified; score 2, the nest looks like a soup plate; score 3, a hemisphere-like nest with a consecutive bank. $(n=5)$; (B) The number of surviving pups was counted on postnatal day 1 to 23 ; (C) The body weight of pups was measured on postnatal day 4 to 23 . Each column represents the mean \pm S.E.M. $(n=5)$. 


\subsection{Blue LED Light Exposure Decreased Visual Function in Maternal Mice}

To clarify whether exposure to blue LED light during the daytime (100 lux for 4 weeks) induces retinal damage in maternal mice, both electrophysiological and histological analysis were performed. Firstly, the effects of blue LED light exposure on visual function in maternal mice were evaluated by electrophysiological analysis. Representative amplitudes of recorded ERG are shown in Figure 2(A). The (a) wave amplitudes indicate the photoreceptor function, and the (b) wave amplitudes reflect the function of bipolar and Müller cells. Therefore, decreases in (a) and (b) wave amplitudes indicate retinal dysfunction (flash intensity 0.98 $\log \mathrm{cd} / \mathrm{m}^{2}$; (a) wave; $p=0.001$, (b) wave; $p=0.012, \mathrm{n}=5$, Figure 2 (B) and Figure $2(\mathrm{C}))$.

(A)

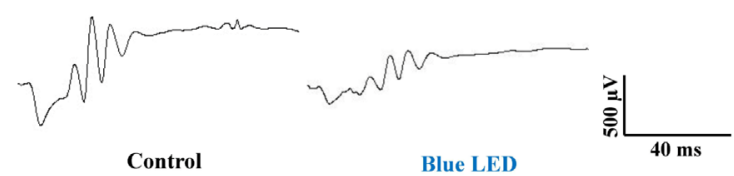

(B)

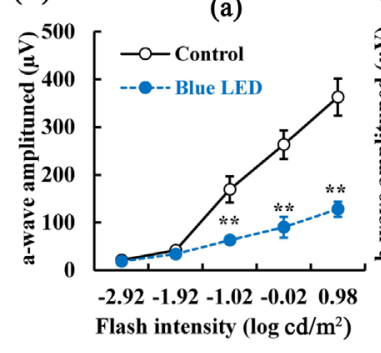

(D)
(C)

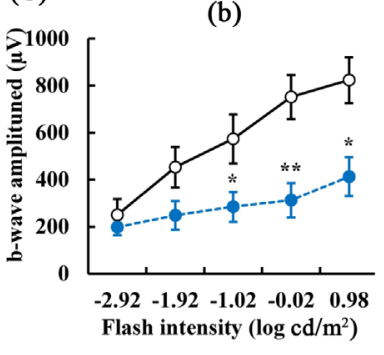

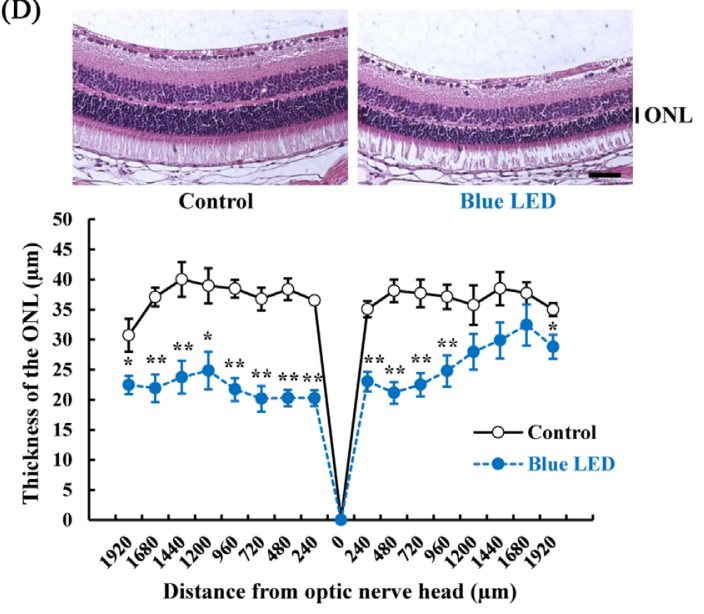

Figure 2. Measurement of retinal function after exposure to blue LED light in maternal mice. (A) Typical traces of dark-adapted ERG responses were measured 7 days after exposure to blue LED light. Stimulus flashes were used from $0.98 \log \mathrm{cds} / \mathrm{m}^{2}$; ((B), (C)) Amplitudes of (a) and (b) waves of blue LED light exposure (100 lux for 4 weeks); (D) Measurement of the thickness of the outer nuclear layer 7 days after blue LED light exposure. Upper images are representative images of retinal sections. Each column represents the mean \pm S.E.M. $(\mathrm{n}=5) .{ }^{*} ; p<0.05,{ }^{*} ; p<0.01$ vs. control group (Student's $t$-test). The horizontal scale bar represents $50 \mathrm{~mm}$. 
Next, the effects of blue LED light exposure on visual function in maternal mice were also evaluated by histological analysis. Representative retinal images from optic nerves of maternal mice were taken 7 days after blue LED light exposure finished (Figure 2(D)). The outer nuclear layer (ONL) in the blue LED light-exposed mice was significantly thinner compared with that in the non-exposed control mice (distances $960 \mu \mathrm{m} ; p=0.0001, \mathrm{n}=5$, Figure 2(D)). The thickness of the ONL was measured at $240 \mu \mathrm{m}$ intervals (Figure 2(D)).

\subsection{Offspring Mice from Blue LED-Exposed Dams Did Not Show Any Behavioral Changes}

Offspring mice were exposed to blue LED light together with their dams during the child-hood period (postnatal day 0 to 21). Male offspring mice were brought up at 12 weeks old in normal light conditions with their littermates. There was no difference in the aver-age body weights of male offspring between each group in 12 weeks old (data not shown). To clarify the effects of blue LED light during the childhood period, behavioral tests were performed. For behavioral tests, total 26 mice ( 2 or 3 mice per cage) were used.

In the open field test, locomotor activity and anxiety-like behavior were evaluated. Distance moved and duration in the center zone of blue LED light-exposed offspring mice did not differ from non-exposed control offspring mice in the open field test (distance moved at $1 \mathrm{~min} ; p=0.08$, duration in the center zone at $1 \mathrm{~min} ; p=0.31, \mathrm{n}=11$, Figure $3(\mathrm{C})$ and Figure $3(\mathrm{D})$ ). The $\mathrm{Y}$-maze test was performed to evaluate short-term memory. The alternation rate and total number of arm entries in blue LED light-exposed offspring mice did not differ from that of non-exposed control offspring mice (alternation rate; $p=0.25$, total number of arm entries; 0.35 , Control; $n=12$, Blue LED; $n=13$, Figure $3(A)$ and Figure 3(B)). The tail suspension test was performed to evaluate depression-like behavior. In a tail suspension test, the immobility time did not change between each group ( 8 min; $p=0.44, \mathrm{n}=11$, Figure $3(\mathrm{E})$ ), suggesting that blue LED light-exposed offspring did not show depression-like behavior.

\subsection{Blue LED Light Did Not Affect Visual Function in Offspring Mice Exposed to Blue LED Light during the Childhood Period}

To assess the effects of blue LED light exposure during the childhood period in offspring mice, retinal functions were evaluated. In male offspring mice, ERG amplitudes (representative amplitudes in Figure 4(A); flash intensity $0.98 \log$ $\mathrm{cd} / \mathrm{m}^{2}$; (a) wave; $\mathrm{p}=0.26$, (b) wave; $p=0.54, \mathrm{n}=6$, Figure $4(\mathrm{~B})$ and Figure $4(\mathrm{C}))$ and ONL thickness did not differ between LED light-exposed and control mice (distances $960 \mu \mathrm{m} ; p=0.11$, Control; $\mathrm{n}=5$, Blue LED; $\mathrm{n}=4$, Figure 4(D)).

\section{Discussion}

In the present study, we hypothesized that blue LED light has harmful effects on maternal mice. However, there was no difference in the nesting behavior or survival rate of pups after exposure to blue LED light, although blue LED light did 
(A)

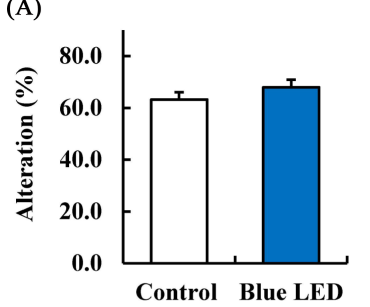

(C)

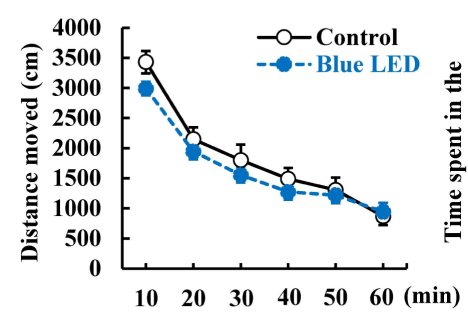

(E)

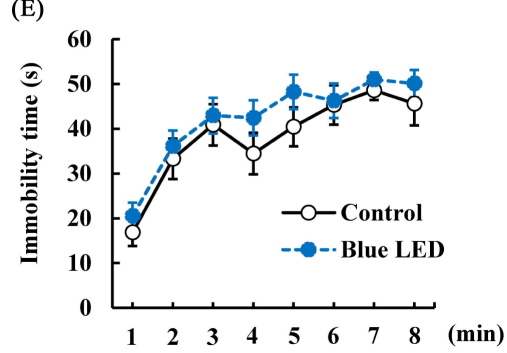

(B)

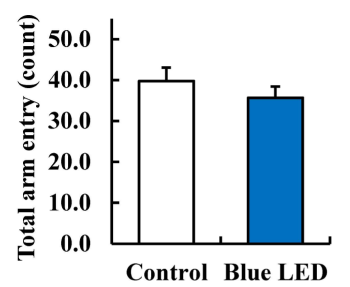

(D)

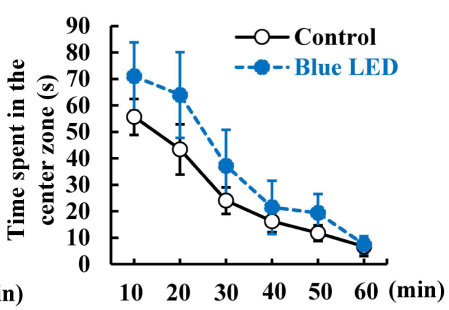

Figure 3. Behavioral analyses of offspring mice after exposure to blue LED light. ((A), (B)) The results of the Y-maze test. (A) The percentage of alternation; (B) Total arm entries in the test. Each column represents the mean \pm S.E.M. Control $(n=12)$, Blue LED light ( $\mathrm{n}=13$ ); ((C), (D)) The results of the open field test; (C) Total distance moved in 15 min in the novel environment; (D) Duration in the center zone $(15 \times 15 \mathrm{~cm})$; (E) Immobility time in the tail suspension test. Each column represents the mean \pm S.E.M. (n $=11)$.

induce retinal damage. These findings suggest that blue LED light does not affect maternal behavior, at least in these experimental conditions.

In previous reports, environmental and genetic factors were known to affect the maternal behavior or survival rate of pups [16] [17]. In housing conditions with $60 \%$ food restriction or in a cold temperature cage, the rate of female weaning or pups surviving significantly decreased in mice [16]. These reports suggest that severe physical and mental conditions disrupt the mother-infant relationship. In the present study, blue LED light exposure might not severely stress dams or pups or affect brain function.

In the present study, although the retinal function was damaged in blue LED light-exposed dams, there was no difference in the behavior of offspring mice. The reason why visual dysfunction in dams did not affect the behavior of offspring mice remains unclear. In a previous report, maternal behavior was impaired in female mice lacking type 3 adenylyl cyclase, which is required for olfactory signal transduction in the main olfactory epithelium [17]. Moreover, maternal behavior was also impaired in the mice after removal of the olfactory 
(A)

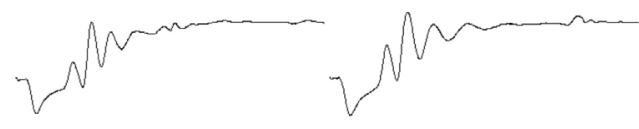

Control

(B)

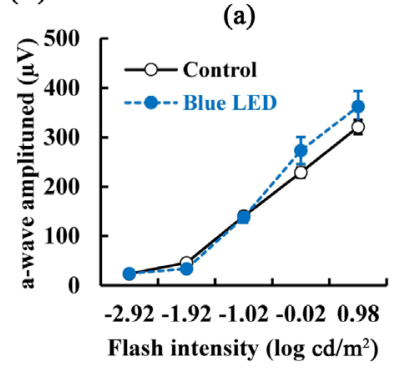

C)

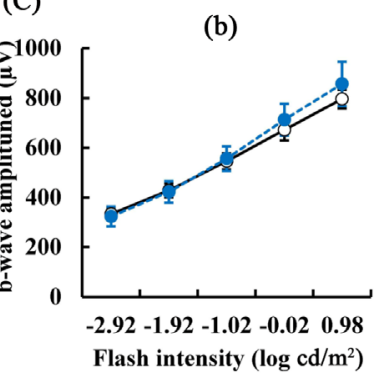

(D)
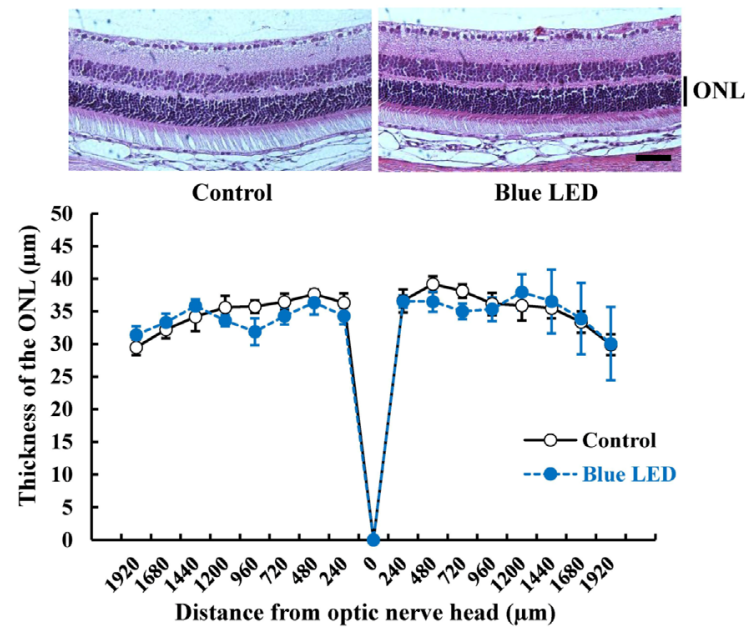

Figure 4. Measurement of retinal function after exposure to blue LED light in offspring mice. (A) Typical traces of dark-adapted ERG responses measured 9 weeks after exposure to blue LED light. Stimulus flashes were used from $0.98 \mathrm{log} \mathrm{cds} / \mathrm{m}^{2}$; ((B), (C)) Amplitudes of (a) and (b) waves of blue LED light exposure (100 lux for 4 weeks); (D) Measurement of the thickness of the outer nuclear layer at 7 days after blue LED light exposure. Upper images are representative images of retinal sections. ONL: outer nuclear layer. Each column represents the mean \pm S.E.M. $(\mathrm{n}=4$ or 5$)$. The horizontal scale bar represents 50 $\mathrm{mm}$.

bulb [18]. Whereas, postpartum female mice showed retrieving behavior after chemosensory cues from pups without the use of audiovisual cues [19] [20]. These reports suggest that olfaction is the most important sense for maternal behavior. The lack of effects on offspring mice in the present study might be due to visual function not significantly contributing to maternal behavior. However, further analyses will be needed to clarify the effects of blue LED light on maternal or offspring mice.

Blue LED light was reported to regulate the circadian rhythm [4] [5]. In previous reports, exposure to light at nighttime, irrespective of the light-dark cycle, was shown to disturb brain functions by disturbing the circadian rhythm [21] 
[22]. Disturbance of the circadian rhythm is a risk factor for type 2 diabetes, bipolar disease, and synaptic plasticity dysfunction in the hippocampus [23] [24] [25]. In a previous study, excessive non-normative stimulation with LED light and noises at nighttime on postnatal day 10 - 42 caused cognitive impairment and hyperactivity in mice [26]. In this report, stimulation with light at nighttime for $6 \mathrm{hr}$ was thought to disrupt the circadian rhythm. However, our previous study demonstrated that exposure to blue LED light for a month did not affect memory function, anxiety, or depression-like behavior in C57BL/6J mice [27]. Since disruption of circadian rhythm leads to various physiological changes, in the present study, exposure to light was performed during the light cycle to avoid secondary effects from disruption of the circadian rhythm. A lack of negative effects in offspring mice indicated that exposure to blue LED light during the daytime might not be a risk factor for dysfunction of brain development in offspring mice. The most major difference between a previous report [26] and the present study was the time at which mice were exposed to light. Therefore, the difference of the time of light exposure might lead to the differences in the effects on brain functions. Light exposure that abides to the light-dark cycle might not be harmful to brain functions. However, further studies are needed to clarify a tolerance condition and a time period during which LED light can be used safely during the pregnancy and lactation periods.

\section{Conclusion}

Blue LED light exposure during the daytime affects visual function, but not behaviors related to maternal care in maternal mice. Nevertheless, blue LED light exposure during the daytime did not affect the retina or brain development in offspring mice. Blue LED light during the daytime might not be a risk factor for disruption of the mother-infant relationship or offspring brain development in mice.

\section{Conflict of Interest}

The authors declare that there is no conflict of interest.

\section{References}

[1] Grimm, C., Wenzel, A., Williams, T., Rol, P., Hafezi, F. and Reme, C. (2001) Rhodopsin-Mediated Blue-Light Damage to the Rat Retina: Effect of Photoreversal of Bleaching. Investigative Ophthalmology \& Visual Science, 42, 497-505.

[2] Kuse, Y., Ogawa, K., Tsuruma, K., Shimazawa, M. and Hara, H. (2014) Damage of Photoreceptor-Derived Cells in Culture Induced by Light Emitting Diode-Derived Blue Light. Scientific Reports, 4, 5223. https://doi.org/10.1038/srep05223

[3] Nakamura, M., Kuse, Y., Tsuruma, K., Shimazawa, M. and Hara H. (2017) The Involvement of the Oxidative Stress in Murine Blue LED Light-Induced Retinal Damage Model. Biological and Pharmaceutical Bulletin, 40, 1219-1225. https://doi.org/10.1248/bpb.b16-01008

[4] Hattar, S., Liao, H.W., Takao, M., Berson, D.M. and Yau, K.W. (2002) Melanopsin-Containing Retinal Ganglion Cells: Architecture, Projections, and Intrinsic 
Photosensitivity. Science, 295, 1065-1070. https://doi.org/10.1126/science.1069609

[5] Tosini, G., Ferguson, I. and Tsubota, K. (2016) Effects of Blue Light on the Circadian System and Eye Physiology. Molecular Vision, 22, 61-72.

[6] Cheung, I.N., Zee, P.C., Shalman, D., Malkani, R.G., Kang, J. and Reid, K.J. (2016) Morning and Evening Blue-Enriched Light Exposure Alters Metabolic Function in Normal Weight Adults. PLoS ONE, 11, e0155601. https://doi.org/10.1371/journal.pone.0155601

[7] Noirot, E. (1969) Serial Order of Maternal Responses in Mice. Animal Behaviour, 17, 547-550. https://doi.org/10.1016/0003-3472(69)90162-6

[8] Numan, M. (1988) Neural Basis of Maternal Behavior in the Rat. Psychoneuroendocrinology, 13, 47-62. https://doi.org/10.1016/0306-4530(88)90006-6

[9] Kuroda, K.O., Tachikawa, K., Yoshida, S., Tsuneoka, Y. and Numan, M. (2011) Neuromolecular Basis of Parental Behavior in Laboratory Mice and Rats: With Special Emphasis on Technical Issues of Using Mouse Genetics. Progress in Neuro-Psychopharmacology \& Biological Psychiatry, 35, 1205-1231.

https://doi.org/10.1016/j.pnpbp.2011.02.008

[10] Li, M., Xue, X., Shao, S., Shao, F. and Wang, W. (2013) Cognitive, Emotional and Neurochemical Effects of Repeated Maternal Separation in Adolescent Rats. Brain Research, 1518, 82-90. https://doi.org/10.1016/j.brainres.2013.04.026

[11] Deacon, R.M. (2006) Assessing Nest Building in Mice. Nature Protocols, 1, $1117-$ 1119. https://doi.org/10.1038/nprot.2006.170

[12] Hess, S.E., Rohr, S., Dufour, B.D., Gaskill, B.N., Pajor, E.A. and Garner, J.P. (2008) Home Improvement: C57BL/6J Mice Given More Naturalistic Nesting Materials Build Better Nests. Journal of the American Association for Laboratory Animal Science, 47, 25-31.

[13] Ishisaka, M., Kakefuda, K., Oyagi, A., Ono, Y., Tsuruma, K., Shimazawa, M., Kitaichi, K. and Hara, H. (2012) Diacylglycerol Kinase Beta Knockout Mice Exhibit Attention-Deficit Behavior and an Abnormal Response on Methylphenidate-Induced Hyperactivity. PLoS One, 7, e37058. https://doi.org/10.1371/journal.pone.0037058

[14] Kakefuda, K., Ishisaka, M., Tsuruma, K., Shimazawa, M. and Hara, H. (2016) Memantine, an NMDA Receptor Antagonist, Improves Working Memory Deficits in DGK Beta Knockout Mice. Neuroscience Letters, 630, 228-232. https://doi.org/10.1016/j.neulet.2016.07.061

[15] Ishisaka, M., Kakefuda, K., Yamauchi, M., Tsuruma, K., Shimazawa, M., Tsuruta, A. and Hara, H. (2011) Luteolin Shows an Antidepressant-Like Effect via Suppressing Endoplasmic Reticulum Stress. Biological and Pharmaceutical Bulletin, 34, 1481 1486. https://doi.org/10.1248/bpb.34.1481

[16] Marsteller, F.A. and Lynch, C.B. (1987) Reproductive Responses to Variation in Temperature and Food Supply by House Mice: II. Lactation. Biology of Reproduction, 37, 844-850. https://doi.org/10.1095/biolreprod37.4.844

[17] Wang, Z. and Storm, D.R. (2011) Maternal Behavior Is Impaired in Female Mice Lacking Type 3 Adenylyl Cyclase. Neuropsychopharmacology, 36, 772-781. https://doi.org/10.1038/npp.2010.211

[18] Gandelman, R., Zarrow, M.X., Denenberg, V.H. and Myers, M. (1971) Olfactory Bulb Removal Eliminates Maternal Behavior in the Mouse. Science, 171, 210-211. https://doi.org/10.1126/science.171.3967.210

[19] Smotherman, W.P., Bell, R.W., Starzec, J., Elias, J. and Zachman, T.A. (1974) Maternal Responses to Infant Vocalizations and Olfactory Cues in Rats and Mice. Behavioral Biology, 12, 55-66. https://doi.org/10.1016/S0091-6773(74)91026-8 
[20] Herrenkohl, L.R. and Rosenberg, P.A. (1972) Exteroceptive Stimulation of Maternal Behavior in the Naive Rat. Physiology \& Behavior, 8, 595-598. https://doi.org/10.1016/0031-9384(72)90080-7

[21] Ma, W.P., Cao, J., Tian, M., Cui, M.H., Han, H.L., Yang, Y.X. and Xu, L. (2007) Exposure to Chronic Constant Light Impairs Spatial Memory and Influences Long-Term Depression in Rats. Journal of Neuroscience Research, 59, 224-230. https://doi.org/10.1016/j.neures.2007.06.1474

[22] Fonken, L.K., Finy, M.S., Walton, J.C., Weil, Z.M., Workman, J.L., Ross, J. and Nelson, R.J. (2009) Influence of Light at Night on Murine Anxiety- and Depressive-Like Responses. Behavioural Brain Research, 205, 349-354. https://doi.org/10.1016/j.bbr.2009.07.001

[23] Melo, M.C., Garcia, R.F., Linhares Neto, V.B., Sa, M.B., de Mesquita, L.M., de Araujo, C.F. and de Bruin, V.M. (2016) Sleep and Circadian Alterations in People at Risk for Bipolar Disorder: A Systematic Review. Journal of Psychiatric Research, 83, 211-219. https://doi.org/10.1016/j.jpsychires.2016.09.005

[24] Chaudhury, D., Wang, L.M. and Colwell, C.S. (2005) Circadian Regulation of Hippocampal Long-Term Potentiation. Journal of Biological Rhythms, 20, 225-236. https://doi.org/10.1177/0748730405276352

[25] Gale, J.E., Cox, H.I., Qian, J., Block, G.D., Colwell, C.S. and Matveyenko, A.V. (2011) Disruption of Circadian Rhythms Accelerates Development of Diabetes through Pancreatic Beta-Cell Loss and Dysfunction. Journal of Biological Rhythms, 26, 423-433. https://doi.org/10.1177/0748730411416341

[26] Christakis, D.A., Ramirez, J.S. and Ramirez, J.M. (2012) Overstimulation of Newborn Mice Leads to Behavioral Differences and Deficits in Cognitive Performance. Scientific Reports, 2, 546. https://doi.org/10.1038/srep00546

[27] Domoto, S., Ohba, T., Yoshino, Y., Horibe, M., Yako, T., Shimazawa, M. and Hara, H. (2017) Exposure to Blue LED Light at Subjective Daytime Does Not Affect the Brain Function in the Pigmented Mice. Journal of Science and Technology in Lighting. (In Press)

\section{Scientific Research Publishing}

\section{Submit or recommend next manuscript to SCIRP and we will provide best} service for you:

Accepting pre-submission inquiries through Email, Facebook, LinkedIn, Twitter, etc. A wide selection of journals (inclusive of 9 subjects, more than 200 journals)

Providing 24-hour high-quality service

User-friendly online submission system

Fair and swift peer-review system

Efficient typesetting and proofreading procedure

Display of the result of downloads and visits, as well as the number of cited articles

Maximum dissemination of your research work

Submit your manuscript at: http://papersubmission.scirp.org/

Or contact jbbs@scirp.org 